Goldschmidt 2021 Abstract

https://doi.org/10.7185/gold2021.5072

\section{The role of ferrous saponite in the formation of sulfur-bearing organic matter on early Earth and early Mars}

\author{
NATSUMI NODA ${ }^{1,2}$, YASUHITO SEKINE ${ }^{3,4}$, YOSHIO \\ TAKAHASHI $^{2}$, HIROSHI SAKUMA ${ }^{5}$, TAKAHIRO KAWAI ${ }^{2}$, \\ MAYUKO NAKAGAWA ${ }^{1}$, NORIO KITADAI ${ }^{6}$, KRISTIN \\ JOHNSON-FINN $^{1}$ AND SHAWN E MCGLYNN ${ }^{1}$ \\ ${ }^{1}$ Tokyo Institute of Technology \\ ${ }^{2}$ The University of Tokyo \\ ${ }^{3}$ Institute of Nature and Environmental Technology, Kanazawa \\ University \\ ${ }^{4}$ Tokyo Institute of Technology, Earth-Life Science Institute \\ ${ }^{5}$ National Institute for Materials Science \\ ${ }^{6}$ Japan Agency for Marine-Earth Science and Technology \\ Presenting Author: natsumi@elsi.jp
}

In-situ $\mathrm{CO}_{2}$ fixation is a key process governing the formation of organic matter on planetary bodies and is a potential source of sulfur-bearing compounds on prebiotic Earth. Through comparison to other solar system objects, such as Mars, we can investigate a variety of geologic environments where abiotic sulfur-bearing organic compounds can form. NASA's Curiosity rover has investigated the existence of sulfur-bearing organic matter on Mars from drilled lacustrine mudstones (Eigenbrode et al., 2018). Although terrestrial sulfur-bearing organic matter is known to originate biogenically (e.g., Canfield, 2001; Werne et al., 2008), few studies have investigated abiotic formation of such organic matter through $\mathrm{CO}_{2}$ fixation.

Here, we investigate the formation of sulfur-bearing organic matter through $\mathrm{CO}_{2}$ fixation in sulfur-rich environments similar to the early Martian surface as an analog to processes on early Earth. Our experiments focus on water-rock interactions between ferrous iron-bearing minerals and an aqueous solution containing carbon dioxide and hydrogen sulfide. We conducted systematic laboratory experiments using four types of ferrous iron-bearing minerals: troilite, iron-nickel alloy, magnetite, and synthetic ferrous saponite. Among them, ferrous saponite is suggested to be widespread on early Mars (Michalski et al., 2015; Chemtob et al., 2017). However, the effective reducing power of ferrous saponite is uninvestigated because of its instability under oxidizing terrestrial conditions. Each mineral powder was enclosed in gas-tight glass vials with sodium bicarbonate solution, carbon dioxide gas, and hydrogen sulfide under anoxic conditions, followed by heating at $90^{\circ} \mathrm{C}$ under normal pressure for 2-4 weeks.

We found production of methanethiol and ethanethiol only in the experiments with iron-nickel alloy and ferrous saponite using gas chromatography mass spectrometry analysis. The results of Scanning transmission X-ray microscopy analysis of ferrous saponite after the experiments show the presence of aliphatic and carboxyl compounds on the surface or within the interlayers of the saponites. These results suggest the possibility that atmospheric carbon dioxide could have been reduced to sulfurbearing organic matter with the presence of ferrous saponite in aqueous environments on early Mars. Similar processes could have occurred during aqueous alteration of mafic rocks in prebiotic early Earth environments. 